\title{
El realismo, el empirismo y el sinequismo de Aristóteles y Peirce
}

Realism, empiricism and synechism of Aristotle and Peirce

0 realismo, o empirismo e o sinequismo de Aristóteles e Peirce

Fecha de entrega: 20 de septiembre de 2014

Fecha de evaluación: 15 de noviembre de 2014

Fecha de aprobación: 15 de diciembre de 2014

Jorge Alejandro Flórez $R^{*}$

\section{Resumen}

Este artículo rastrea la presencia del realismo, el empirismo y el sinequismo en las teorías de la cognición de Aristóteles y de Charles S. Peirce. Los dos primeros términos se relacionan comúnmente con ambos autores, pero aquí se quiere precisar en detalle qué semejanzas y diferencias hay entre el realismo y el empirismo de estos dos filósofos. De otro lado, el sinequismo se relaciona solo con Peirce, mientras que a Aristóteles se le ubica precisamente como opositor a cualquier idea de continuidad e infinito. Lo que se quiere mostrar aquí es que, al menos en el ámbito de la cognición, Aristóteles es también un sinequista. Otro punto importante del artículo es que intenta criticar y corregir la interpretación que hace Peirce del empirismo de Aristóteles al intentar erróneamente de afirmar que el filósofo griego es un intuicionista.

\footnotetext{
Profesor titular de la Universidad de Caldas, Doctor en filosofía de Southern Illinois University Carbondale; su maestría y pregrado en filosofia los obtuvo en la Universidad Pontificia Bolivariana de Medellin. En recientes investigaciones trata el pragmatismo norteamericano y en especial la relación de la semiótica de Peirce con la lógica de Aristóteles, del cual este artículo constituye un significativo avance.
} 
Palabras clave: realismo, empirismo, sinequismo, Aristóteles, Charles

S. Peirce, percepción, juicio perceptual.

\section{Abstract}

This paper aims to track the presence of the terms realism, empiricism and synechism in Aristotle's and Peirce's theories of cognition. The two first terms have been usually related to both authors, however in this article it is intended to expose at detail what similarities and differences there are between these two philosophers' realism and empiricism. On the other hand, synechim is only related to Peirce's philosophy, whereas Aristotle is pointed out precisely as a contradictor of any idea of continuum or infinitum. What is meant to show in the paper is that, at least in the field of cognition, Aristotle is also a synechist. Another important point of this article is that attempt to criticize and correct Peirce's interpretation of Aristotle's empiricism due to the fact that former claims erroneously that latter is an intuitionist.

Keywords: Realism, empiricism, synechism, Aristotle, Charles S. Peirce, perception, perceptual judgment.

\section{Resumo}

Este artigo busca a presença do realismo, do empirismo e do sinequismo nas teorias da cognição de Aristóteles e de Charles S. Peirce. Os dois primeiros términos se relacionam comumente a ambos os autores, mas aqui é necessário deixar em evidência que há semelhanças e diferenças entre o realismo e o empirismo destes dois filósofos. Por outro lado, o sinequismo é relacionado somente a Peirce, enquanto que o estagirita, Aristóteles, se localiza do lado oposto de qualquer ideia de continuidade e infinito. O que se pretende é mostrar que ao menos no âmbito da cognição, Aristóteles também é um sinequista. Outro ponto importante do artigo é a critica e tentativa de correção da interpretação feita por Peirce em relação ao empirismo de Aristóteles, o qual, erroneamente, afirma que o filósofo grego é um intuicionista.

Palavras-chave: Realismo, empirismo, sinequismo, Aristóteles, Charles S. Peirce, percepção, juízo perceptivo. 
Este artículo continúa ciertas ideas explorados en otro artículo sobre el sinequismo, el empirismo y el realismo en la filosofía de Charles Peirce (Flórez, 2013, p. 233). En esta ocasión se rastreará la presencia de estos mismos conceptos en la filosofía de Aristóteles y compararlos con los de Peirce. El propio Peirce se ha autodenominado como un "un aristotélico del ala escolástica" que se acerca al escotismo, pero yendo “más allá en la dirección del realismo escolástico" (Peirce, 2012, p. 243). En efecto, en muchos casos, sigue la postura de Aristóteles. Sin embargo, en otras ocasiones critica a Aristóteles por su rechazo a las regresiones al infinito que lo llevan a rechazar el principio sinequista y por su aceptación de una capacidad intelectual intuitiva que lo llevan rechazar el empirismo. Estas afirmaciones me parecen una mala interpretación de la filosofía aristotélica por parte de Peirce. Por el contrario, considero que en el ámbito de la teoría de la cognición ambos filósofos coinciden en ser sinequistas, realistas y empiristas, aunque con algunas leves diferencias.

Que Aristóteles es un realista no es negado por nadie, debido a que es claro que su postura, a veces denominada como un realismo ingenuo, afirma que nuestras sensaciones y concepciones corresponden a realidades externas. Sin embargo, que la teoría del conocimiento en Aristóteles es sinequista y empirista son afirmaciones más polémicas, debido a que la mayoría de los estudiosos sostienen que Aristóteles mantenía una división entre la sensación y el nous, y por lo tanto que no hay continuidad entre ellos. En consecuencia, Aristóteles no podía argumentar a favor de un origen empírico del conocimiento universal y necesario (episteme), cuyo único origen sería únicamente la intuición noética. De acuerdo con esas interpretaciones, Aristóteles no puede caracterizarse como un sinequista o un empirista.

Debido a que la caracterización de Aristóteles como realista no es problemática, no nos detendremos mucho en considerar esto. En primer lugar, se describirán los argumentos que tiene Aristóteles para fundamentar su creencia en la existencia de realidades externas, tanto particulares como universales y, en segundo lugar, se expondrán los argumentos similares que estos dos filósofos emplean para inferir la existencia de una realidad externa de la compulsividad de la experiencia sensible.

Con respecto al sinequismo y al empirismo, se hará una consideración más detallada. La idea a defender aquí es que existe una semejanza entre la idea de Aristóteles de la mutua interdependencia entre la sensación y el nous y la creencia de Peirce en la continuidad entre la percepción sensorial y la lógica. Considerando que a pesar de que la sensación y el nous son estudiados de forma independiente por Aristóteles, 
se complementan entre sí y trabajan mutuamente con el fin de dar una explicación compleja de la cognición humana. La sensación funciona gracias a "un sentido común", que solo puede explicarse por medio de una agencia intelectual atribuible al nous. Del mismo modo, el nous solo puede dar cuenta de sus conocimientos epistemológicos y universales gracias a los datos empíricos que recibe de la percepción sensorial. Esta explicación funciona tanto para una justificación sinequista y empirista de la cognición.

\section{El realismo de Aristóteles y Peirce}

El realismo de Peirce se basa en su teoría según la cual la cognición implica una tríada de objeto, percipuum y el concepto. Para Peirce es indudable que existe un objeto externo independiente de nuestra cognición y que limita nuestras percepciones e interpretaciones sobre él. La realidad del objeto externo e independiente no es una creencia deriva de la necesidad de tener tres elementos en la cognición, sino que se evidencia de la compulsividad de su presencia sobre nuestros sentidos, de la cual no somos responsables. El argumento de Peirce es el siguiente:

Basta decir que quien percibe es consciente de ser compelido a percibir lo que él percibe. Ahora existencia significa precisamente el ejercicio de la compulsión. En consecuencia, cualquiera que sea la característica del percepto se pone de relieve por alguna asociación y así alcanza una posición lógica como la de la premisa observacional de una abducción explicativa, la atribución de la Existencia a ella en el juicio perceptual es virtualmente y en un sentido amplio, una inferencia lógica abductiva que se aproxima a la inferencia nece$\operatorname{saria}^{1}$ (CP 4.541).

En otro lugar dice:

Pero cuando digo que ser realmente es diferente de ser representado, quiero decir que lo que realmente es consiste finalmente en lo que se nos habrá de imponer en la experiencia, que hay un elemento de compulsión bruta en los hechos, y que el hecho no es una mera cuestión de razonabilidad (Peirce, 2012, p. 245).

1 Traducción del autor. 
Este elemento de compulsividad del objeto dinámico es, en principio, el mismo argumento que Aristóteles utiliza para establecer una creencia en la existencia de la realidad externa. Para él, la sensación es una potencialidad, es decir, su ser no es en acto. Un órgano de los sentidos es pasivo y por tanto, solo está en potencia de llegar a sentir. La realidad de la sensación en acto, a saber, el hecho de que una sensación esté teniendo lugar, se debe únicamente a la presencia de un objeto externo. Esto significa que los sentidos no pueden percibir nada a menos que estén en contacto con algo externo. Ahora bien, es un hecho que percibimos, por lo tanto, tiene que haber un objeto externo que cause esa percepción. Aristóteles lo establece de la siguiente manera: "los objetos que excitan la actividad de los poderes sensibles, lo visto, lo oído, etc., están fuera (exothen) [...] no está en poder del hombre experimentar sensaciones"2 (Aristóteles, De Anima, 417b, pp. 21-22; 25).

Los realismos de Peirce y Aristóteles coinciden también en ser no solo una especie de realismo epistemológico, es decir, la doctrina según la cual existe una realidad externa a nuestra conciencia, sino también un realismo ontológico, es decir, la doctrina según la cual hay realidades universales. El realismo ontológico de ambos no es tan extremo como el de Platón, quien sostuvo que las realidades universales son primordiales sobre cualquier otro tipo de realidad. Por el contrario, sostuvieron que existen tanto los particulares como los generales. Tanto Aristóteles como Peirce creen que hay realidades generales y universales. De hecho, Peirce se reconoce a sí mismo como un aristotélico en este respecto, diciendo que lo es según el ala de Duns Escoto en cuanto al realismo, como se mencionó al principio de este artículo.

Obviamente, existen algunas diferencias, pero en el panorama general de una versión realista de los objetos generales y universales, ambos filósofos coinciden. La distinción entre lo general y lo universal es precisamente el punto de diferencia. Aristóteles, siguiendo a su maestro Platón, cree que hay realidades universales, que son eternas e inmutables. Pero, a diferencia de Platón, Aristóteles considera que esas realidades existen principalmente en composición con la materia. La denominación ontológica que le dio a los universales es Forma $(e i)=$ doj), que, si bien se encuentra solo en los individuos particulares como un compuesto con la materia, es el elemento universal que cada individuo comparte con los de su propia especie.

2 Ibíd. 
En vez de argumentar en favor de los universales, Peirce defendió la realidad de los generales. Se refiere a los principios generales activos que operan en la naturaleza (Peirce, 2012, pp. 244-246). Estas son las tendencias regulares de la naturaleza que se revelan como leyes. No son ni universales ni eternas, porque están sujetas a un elemento de tiquismo que puede hacer que cambien y evolucionen. Hay, sin embargo, un elemento que Aristóteles y Peirce comparten en la defensa del realismo ontológico, es decir, su argumento de que las realidades generales y universales son necesarias para la inteligibilidad del mundo. Peirce afirma que "es solo al general al que podemos entender" (Peirce, 2012, p. 244). Se refiere a que solo los objetos de naturaleza general, lo que él denomina como terceridad, son capaces de ser comprendidos, y que la inteligibilidad del mundo es posible porque hay elementos generales. Que la generalidad es el único elemento capaz de brindar inteligibilidad, es el mismo argumento que Aristóteles emplea cuando dice que el objeto de la ciencia, tanto de la episteme como del nous, es general y que de los particulares no hay ciencia. De hecho, Peirce relaciona el concepto de Nous con su categoría de terceridad. No menciona si se trata del uso de este concepto por parte de Anaxágoras, Platón, Aristóteles o Plotino, pero me parece que Aristóteles encaja perfectamente con el requisito de Peirce de inteligibilidad.

Aristóteles afirma explícitamente que "todo conocimiento es de los universales" (Aristóteles, Metafísica, 1086b, pp. 33-34). Además, afirma que un mundo nominalista y atomista sería ininteligible. Su argumento es el siguiente:

\footnotetext{
Si no hay nada aparte de las cosas individuales y si los individuos son infinitos en número, entonces, ¿cómo es posible conseguir el conocimiento (episteme) de los individuos infinitos? Pues todas las cosas que hemos llegado a conocer, las conocemos en la medida en que tienen cierta unidad e identidad, y cierto carácter universal (Aristóteles, Metafísica, 999a, pp. 26-28; Cf. 999b, p. 27).
}

Aristóteles reconoce que este es el mismo argumento que Platón utiliza para apoyar la existencia de las ideas (Aristóteles, Metafísica, 990b, pp. 11-14; 1078b, pp. 15-16), pero no concluye como Platón que existen ideas universales separadas e independientes, sino que debe existir la universalidad en el mundo. De lo contrario no sería posible entender y conocer. 


\section{El empirismo de Aristóteles y de Peirce}

La teoría aristotélica de la cognición, expuesta en los Analíticos Segundos II 19 y en la Metafísica I, 1, es empirista sin lugar a dudas. Allí se describe el proceso cognitivo como un proceso empírico iniciado en la sensación, la memoria y la experiencia en general, y concluido en el nivel racional de las artes (techne), las ciencias (episteme) y el intelecto (nous). La manera en que describe al nous algunas veces lo lleva a parecer un dualista, pues lo describe como algo radicalmente distinto de la percepción sensible. Por ejemplo, dice que el nous es "separable, impasible y sin mezcla" (Aristóteles, De Anima III, p. 5). Sin embargo, existe mucha mayor evidencia en contra de esto; evidencia que indica que hay una mutua conectividad y cooperación entre la sensación y nous en Aristóteles. Por lo tanto, con el fin de exponer su empirismo, comenzaremos con la primera etapa del proceso cognitivo, a saber la sensación. Más tarde, para exponer su sinequismo, se abordará la interdependencia y la continuidad entre la sensación y el nous.

Es evidente que ambos filósofos coinciden en su postulación de la sensación como la primera etapa del proceso cognitivo. Sin embargo, el hecho de que ambos filósofos son empiristas no implica que sus explicaciones de la percepción sean iguales. Iniciemos describiendo la postura del filósofo norteamericano. Peirce está de acuerdo con la afirmación de Locke según la cual el origen del conocimiento está en la percepción sensible, pero no está de acuerdo en relación con el proceso de percibir. Es decir, el empirismo de Peirce es diferente al de Locke y al del resto de empiristas ingleses quienes usan este empirismo para fundamentar su nominalismo. En cambio, el empirismo de Peirce se acerca mucho más al de Aristóteles, no solo en afirmar que la experiencia es la fuente de todo tipo de conocimiento, sino también en la manera como explican la percepción como una fuente de conocimiento tanto particular como general. Asimismo ambos coinciden en atribuir un carácter crítico a la percepción que los empiristas modernos niegan.

Ambos filósofos pensaban que la sensación consiste en la afirmación de que lo que percibimos es algo. Sin embargo, en este punto la coincidencia no es completa, ya que para Peirce cada sensación puede ser juzgada, y cada sensación incluye primeridad, segundidad y terceridad. Por el contrario, Aristóteles divide a la sensación en dos formas, ya sea propia o accidental. La sensación propia incluye solo la percepción de las cualidades que cada sentido puede percibir, es decir, es la percepción de la primeridad 
y tal vez de la segundidad si incluimos la afirmación de que lo que percibimos es una cosa real e independiente. Esta es la razón por la que Peirce critica correctamente a Aristóteles por concebir la percepción como directa o inmediata (Cf. CP 7, p. 639), mientras que Peirce mismo sostiene que el juicio perceptual o percipuum es siempre mediado, es decir, es una terceridad. Aristóteles de hecho pensaba que la percepción propia es una percepción inmediata de una calidad, y que estas percepciones propias siempre son correctas. Sin embargo, parece que Peirce en su crítica pasó por alto la teoría aristotélica del sensible accidental, el cual funciona como una sensación mediada o un juicio perceptual, y por lo tanto, es una terceridad.

La teoría aristotélica del sensible accidental parece ser una anticipación rudimentaria de la teoría peirceana de los juicios perceptual. Una sensación accidental consiste en el juicio de que el percepto es una de las diez categorías aristotélicas. Por ejemplo, se juzga que el percepto blanco es "el hijo de Diare" o un "hombre". Así, en una sensación accidental se puede predicar que un percepto es una relación o que pertenece a un género universal (sustancia secundaria o generales). Esto es precisamente lo que la teoría peirceana de los juicios perceptuales establece, es decir, que a un percepto se le predica un concepto y se forma un juicio perceptual. En términos de sus categorías se explica de la siguiente manera: un percepto (primeridad) se relaciona con un concepto (segundidad) a través de un juicio (terceridad). Aunque la sensación se descompone teóricamente en estos tres elementos, en realidad la sensación siempre se da en el conjunto triádico, es decir, la sensación se da siempre en juicios perceptuales o terceridades.

La teoría del sensible accidental en Aristóteles y la teoría de los juicios perceptuales en Peirce, son tan similares que ambos afirman que este tipo de sensación es susceptible de ser verdadera o falsa. Siempre es posible que el concepto que se relacione con un percepto no sea correcto; por ejemplo, si veo una cosa blanca (percepto) y juzgo que es "el hijo de Diares" (concepto) pero en realidad era otra persona, entonces mi juicio perceptual es falso. La debilidad de la mediación del juicio perceptual la atribuye Peirce al hecho de que este es un tipo de inferencia abductiva cuyos resultados son solo posibles (Peirce, 2012, Vol II., p. 294). Igualmente, tanto Peirce como Aristóteles afirman que el percepto y el sensible propio son siempre verdaderos.

Asimismo, las soluciones que Aristóteles propone para las dificultades que conlleva la distinción entre la sensación propia y accidental acercan aún más a Aristóteles al sinequismo y el empirismo periceano. Por ejemplo, la teoría de una percepción propia 
con la cual es posible percibir únicamente cualidades individuales e inmediatas hace que Aristóteles se pregunte cómo es posible percibir cualidades simultáneas y que se pueda juzgar que pertenecen a una sustancia única. Su respuesta es que hay un "sentido común" o "sentido primario" que no posee un órgano de los sentidos, pero es responsable de la unificación de la percepción de todos los otros sentidos y responsable de la percepción de la unidad de una sustancia (Aristóteles, De Anima, 425a, p. 28; 425b2). El "sentido común" es una agencia intelectual o noética que permite que la percepción tenga lugar. El hecho de que percibe cualidades simultáneamente o que encuentra relaciones entre cualidades es una indicación que corresponde a la categoría de Peirce de Segundidad. Esto quiere decir que Aristóteles también ofrece una explicación de la percepción de las reacciones y relaciones. Del mismo modo, no solo es posible que la sensación accidental predique un concepto universal de un percepto, sino que también el nous es capaz de comprender lo universal a través de la información que recibe de percepción de las cualidades y del "sentido común". Por otra parte, Aristóteles también afirma que podamos percibir los universales: "la sensación es sobre universal, como por ejemplo el hombre, y no el hombre Kallias" (Aristóteles, Analíticos Segundos, 100b, pp. 1-2). (Cf. Ética a Nicómaco 1143b, pp. 4-5). En consecuencia, Aristóteles también ofrece una explicación con respecto a la percepción de lo general o la terceridad.

Si seguimos el argumento de Peirce según el cual la generalidad o la terceridad se encuentran en la percepción debido a que el predicado que se le adjunta a cada percepto en el juicio perceptual es general, entonces podemos concluir que Aristóteles también aplica la terceridad a cada percepción, pues Aristóteles también considera que todo tipo de sensación, no solo la accidental, es judicativa. Afirma que la sensación juzga (krinein) acerca de su objeto propio de percepción. Además, afirma que la sensación es una afirmación, y que incluso los animales afirman algunas cosas acerca de sus percepciones, como que son agradables o desagradables.

En conclusión, Aristóteles y Peirce ofrecen explicaciones similares de la percepción como juicio perceptual de cualquier tipo de realidad, ya sea particular o general. La diferencia entre estas teorías de la percepción es que Peirce incluye todo tipo de percepción dentro de una única explicación general de la relación triádica entre percepto, concepto y juicio perceptual. En contraste, Aristóteles divide la percepción en dos grupos, a saber, la percepción propia que solo percibe cualidades simples, y la percepción accidental que percibe también relaciones y generalidades. La percepción 
propia según Aristóteles corresponde al percepto de Peirce en la medida en que ambos dan cuenta de la percepción inmediata de cualidades, y son, además de inmediatos, siempre verdaderos. En cambio, la percepción accidental de Aristóteles corresponde al juicio perceptual de Peirce en la medida en que es siempre mediada y puede ser verdadera o falsa. Para ser más específicos, la diferencia es que Aristóteles considera la percepción propia y la accidental como dos eventos diferentes. En cambio, Peirce considera que el percepto es solo la primeridad del proceso completo que da como resultado un juicio perceptual. La sensación es una terceridad, es decir una mediación, o como él mismo lo indica, una interpretación, en la que el percepto es mediado a través del juicio perceptual (Peirce, 2012, Vol II., p. 296). Solo podemos prescindir de la percepción del juicio perceptual con una abstracción mental, pero nuestra experiencia real de la percepción es siempre mediada por juicios perceptuales.

A pesar de estas diferencias, ambas teorías explican cómo percibimos cualidades individuales, diferencias entre estas cualidades y cómo percibimos relaciones de estas cualidades con conceptos más generales. Aunque Peirce hace una explicación unificada de la percepción, mientras que Aristóteles distingue dos tipos de percepciones, ambos filósofos consideran que los particulares y los generales son objetos de la percepción sensorial. Si Peirce hubiera ofrecido una clasificación de las teorías de la percepción, como lo hizo con los sistemas metafísicos (Ibíd., p. 243), habría dicho que él y Aristóteles se ubican entre los pocos filósofos que aceptan la percepción de las tres categorías.

Ambos filósofos son empiristas porque afirman que la experiencia sensible nos es solo el origen del conocimiento de los particulares, sino también el origen y la fuente de cualquier otro tipo de conocimiento. Aristóteles ha sido usualmente interpretado como un dualista. El mismo Peirce afirma que Aristóteles postula de forma contradictoria a la experiencia sensible como la fuente de conocimiento y al mismo tiempo explica el origen de los primeros principios a partir de la intuición o como proposiciones autoevidentes. La intensión es corregir esta interpretación, porque hay suficiente evidencia que sugiere que Aristóteles quería fundar el origen del conocimiento únicamente en la experiencia sensorial. Aristóteles considera que la sensación y el intelecto -nous- son diferentes; sin embargo, afirma que toda la actividad del intelecto debe basarse en la experiencia. El intelecto no puede pensar sin imágenes, que proceden de la sensación. De la misma manera, su estudio del alma indica que debe haber una unidad, y que por lo tanto, la sensación y el intelecto son solo dos aspectos de un alma que se puede dividir teóricamente. Por otra parte, el 
estudio de Aristóteles de otros aspectos de nuestras capacidades cognitivas mostró que existe una dependencia mutua entre la sensación y el intelecto. Por ejemplo, Aristóteles explica la posibilidad de percibir los sensibles comunes, los sensibles accidentales, las cualidades simultáneas de una sustancia única, o las experiencias del pasado, gracias a lo que él llama "el sentido común". Señala que este sentido común pertenece a la parte sensible del alma, pero este requiere una agencia intelectual que le permita juzgar y comparar.

Peirce es también un empirista dado que acepta el principio según el cual no hay nada en el intelecto que no pase primero por los sentidos. Sin embargo, ni Aristóteles ni Peirce son empiristas en el sentido moderno del término. Ambos filósofos consideran que hay elementos intelectuales en la percepción. Aristóteles afirmaba que en última instancia es el nous el que conoce; recibe los datos de la percepción y la experiencia y capta la realidad. Por eso no es erróneo decir que Aristóteles es a la vez un empirista y un racionalista. Peirce, por su parte, declara expresamente que la experiencia es tanto empírica como interpretativa, de este modo su posición se encuentra también en algún lugar entre el empirismo y el idealismo. Para él, la experiencia sensible es la fuente de todo tipo de conocimientos, pero no niega el elemento subjetivo de la cognición. A diferencia de Aristóteles, Peirce afirma que la subjetividad de la cognición está presente en el ámbito primordial de la percepción, la cual, dijo, es siempre interpretativa, ya que siempre se presenta en los juicios de percepción. Para Aristóteles es solo la sensación accidental la que es judicativa, pero es evidente por otras afirmaciones implícitas que él considera que todo tipo de sensación es judicativa. Juzgar es una actividad exclusiva del intelecto, y es por eso que la percepción de Aristóteles requiere una agencia noética para ser plenamente explicado.

\section{El sinequismo de Aristóteles y Peirce}

Ambos filósofos creen que toda concepción cognitiva es una concepción intelectual o racional que se origina en la experiencia sensible en un proceso continuo. Peirce sostuvo que todo el proceso de la cognición no solo es continuo, por lo que evita la paradoja de una regresión ad infinitum, sino que también es integral dado que la percepción de la generalidad se da incluso al nivel de los juicios de percepción, con lo que evita el requisito de explicar la adquisición de conceptos generales. Aristóteles considera también que el proceso es continuo desde la percepción sensorial hasta el nous. Aunque carecía de la idea peirceana de continuidad con todos sus componentes 
matemáticos y su requisito de aceptar el infinito, Aristóteles sostiene que hay una dependencia mutua entre el nous y la sensación que hace del proceso un todo integral. Más específicamente, el sinequismo atribuido aquí a Aristóteles es solo del proceso cognitivo, pues Aristóteles es, por el contrario, uno de los más grandes opositores de la idea de continuo y de la infinitud en la naturaleza. Cuando aquí se afirma que las teorías de Aristóteles y de Peirce acerca de la cognición son sinequistas, lo que se quiere decir es que no son dualistas, sino que representan un proceso integral en el que todos los componentes son mutuamente dependientes.

El sinequismo de Aristóteles en el proceso cognitivo lo sustento en tres argumentos principales. En primer lugar, no existe tal dualismo entre la sensación y el nous, pues Aristóteles afirma que "la sensación, la experiencia, el arte o epistēmē son el nous" (Aristóteles, Ética a Nicómaco, 1143b, pp. 4-5). En los Analíticos Posteriores dice que “el nous es el principio (arjé) de la epistēmē” (Aristóteles, Analíticos Segundos, 88b, p. 36). Del mismo modo, en De Sensu, dice que "el nous no piensa objetos externos que no estén conectados con la sensación” (Aristóteles, De sensu, 445b, p. 18).

En segundo lugar, la necesidad de una unidad en el alma humana obliga a que la distinción entre las partes sensible e intelectual sea más una distinción conceptual en lugar de una separación real. A partir de De Anima, está claro que para Aristóteles el alma tiene que ser una unidad que dé cuenta de todas las características que están presentes en los seres vivos: el crecimiento, la reproducción, la sensación, el deseo y el pensamiento. El alma, al igual que las figuras geométricas, tiene diferentes formas, pero una definición común de todos ellos es posible. Así, el alma tiene diferentes partes, pero se puede definir, Aristóteles creía, como aquello que actualiza un cuerpo vivo en diferentes aspectos, dependiendo de las posibilidades del cuerpo. Las diferentes partes del alma no son diferentes tipos de almas colocadas de alguna manera en un ser vivo, sino diferentes actualizaciones de un alma única en cada individuo. Las demarcaciones de las diferentes partes del alma son más conceptuales que reales. Brentano insistió en esto como se puede ver en la siguiente cita:

[L] a parte intelectual del hombre forma una sola sustancia con la parte corporal. El alma intelectual y el alma vegetativa-sensitiva no son dos almas; no ellas son una sola forma, que en parte anima al cuerpo, pero que en parte es también libre del cuerpo, e intelectual ${ }^{3}$ (Brentano, 1977, p. 132).

3 Traducción del autor. 
En tercer lugar, se encuentran los diversos fenómenos señalados por Aristóteles en los cuales las partes del alma son mutuamente dependientes. El primero de estos fenómenos es la postulación del sentido común para explicar nuestra capacidad de percibir cualidades simultáneas en un solo individuo, y para explicar la capacidad de tener sensaciones accidentales. Para Aristóteles, la sensación por sí sola no puede explicar satisfactoriamente incluso el hecho de que percibimos las cualidades de una sustancia única. La sensación propia solo proporciona una explicación de la percepción de cualidades aisladas. El hecho de que experimentamos una multiplicidad de cualidades simultáneas de una sustancia única, se explica por Aristóteles de postular un "sentido común" o "sentido primario" que unifique toda la multiplicidad. Este "sentido común" es la acción noética, es decir, un acto intelectual que la sensación no puede hacer. Como resultado, esta es una de las primeras acciones en las que se requiere la interacción mutua entre la sensación y el nous. Además, cuando Aristóteles proporciona una explicación de cómo es que el pensamiento nous tiene lugar, afirma que solo puede pensar con las imágenes proporcionadas por la sensación. En otras palabras, el nous es una capacidad intelectual que depende de la sensación.

Otro fenómeno que revela la mutua dependencia y continuidad entre las partes del alma que juegan un papel importante en el proceso cognitivo es la relación inquebrantable entre el nous y la imaginación, que a su vez depende de la sensación. El pensamiento no puede tener lugar sin imágenes, y las imágenes no pueden tener lugar sin la sensación. Por lo tanto, el pensamiento no puede tener lugar sin la sensación.

El principio del sinequismo que Peirce aplica a todos los ámbitos de la realidad, lo aplica, obviamente, también a la cognición. Este considera que el conocimiento es un continuo desde las percepciones hasta las concepciones. Para él, todo conocimiento está determinado por otros conocimientos previos, y que se pasa del uno al otro a través de procesos que se pueden representar como inferencias. Estas ideas van directamente en contra de una facultad intuitiva que permita adquirir conocimiento inmediato. De hecho, Peirce acusa, entre otros, a Aristóteles de ser intuicionista y de creer que existe conocimiento inmediato y autoevidente. Además lo causa de haber sido el que introdujo en filosofía la paradoja falaz según la cual la fundación de todo conocimiento epistémico debe ser apodícticamente demostrado. Esta paradoja consiste en considerar que si toda demostración debe ser soportada propiamente por premisas ciertas y previamente conocidas, entonces, sería necesario asegurar también la certeza de estas premisas por medio de demostraciones apodícticas, y 
así sucesivamente en una regresión al infinito. Para evitar esta regresión al infinito, los seguidores de esta falacia postulan principios tales como el nous, la intuición o la luz natural.

Peirce considera que esta paradoja del conocimiento es la misma paradoja de Zenón sobre Aquiles y la tortuga, (Cf. W1, p. 490; CP 2, p. 27) con la diferencia de que mientras la paradoja de Zenón impide la posibilidad de movimiento hacia adelante, la paradoja del conocimiento impide la posibilidad de obtener conocimiento, pues requeriría moverse hacia atrás para obtener un número infinito de premisas previas antes de demostrar una conclusión concreta. Ambas paradojas, dice Peirce, cometen la falacia de confundir cantidades discretas con cantidades continuas. Si en realidad el espacio estuviera compuesto de partes infinitas desligadas, entonces Aquiles no podría nunca alcanzar a la tortuga y esta última no podría ni siquiera moverse.

De igual manera, si el proceso cognitivo estuviera compuesto de una sucesión infinita de silogismos demostrativos, o de esfuerzos mentales discretos, entonces no se podría ni siquiera afirmar nada. Por el contario, Peirce afirma: "no hay en absoluto una primera cognición, sino que la cognición surge en un proceso continuo" (EP I, p. 30) En otro lugar dice: "no se sigue que porque no ha habido un primer elemento en una serie, entonces que la serie no tiene un comienzo en el tiempo; pues la serie puede ser continua, y puede haber comenzado gradualmente" (EP I, p. 61).

En consecuencia, toda nueva cognición, creencia o concepción llega a nuestra conciencia por medio de alguna creencia previa que se establece como premisa. Toda actividad cognitiva es inferencial y continúa incluso los juicios perceptuales. El hecho que no seamos conscientes de estos procesos no significa que no tenga lugar de esta forma.

En síntesis, es posible afirmar que ambos filósofos son sinequistas en el ámbito cognitivo. Aunque a Aristóteles le faltaba el concepto matemático de un continuo y no dio importancia filosófica a la idea de infinito, considera que la reacción entre sensación e intelecto es continua. Las quejas que tiene Peirce contra Aristóteles por caer en la paradojas del movimiento se aplican al conocimiento demostrativo por el cual Aristóteles postuló la existencia del nous que revela los primeros principios de las ciencias, pero este nous no es una intuición que descubra principios sin conocimientos previos. El nous o intelecto aristotélico funciona a través de los datos de la sensación y la imaginación y lo hace a través de un proceso inductivo. Postuló el nous precisamente porque pensaba que una demostración infinita era imposible y 
porque creía que los primeros principios de la ciencia debían originarse de otro modo distinto al demostrativo. No obstante, Aristóteles hace una explicación sinequista de la cognición en la medida en que piensa que hay una dependencia mutua y una continuidad evidente entre la sensación y el nous.

\section{Referencias}

. (2001). The Basic Works of Aristotle. Edited by Richard Mckeon. New York: The Modern Library.

. (1998). Ética a Nicómaco y Ética Eudemia. Biblioteca Clásica Griega No. 89. Introducción por Emilio Lledó. Traducción y Notas por: Julio Pallí Bonet. Madrid: Gredos.

. (2002). Ética Nicómaco. Edición Bilingüe y traducción por María Araujo y Julián Marías. Madrid: Centro de Estudios Políticos y Constitucionales.

. (1990). Metafísica. Edición poliglota por Valentín García Yebra. 2a . ed. Madrid: Gredos.

. (2000). On the Soul, Parva Naturalia, On Breath. Loeb Classical Library, No.

288. Translated by W.S. Hett. Cambridge, Massachusetts: Harvard University Press. . (1960). Posterior Analytica, Topica. Loeb Classical Library, No. 391. Translated by Hugh Tredennick and E.S. Foster. Cambridge, Massachusetts: Harvard University Press.

. (1994). Tratados de Lógica (Organón) I: Categorías, tópicos, sobre las refutaciones sofísticas. Biblioteca Clásica Griega No. 51. Introducciones, traducciones y notas por: Miguel Candel Sanmartín. Madrid: Gredos.

. (1995). Tratados de Lógica (Organón) II: Sobre la interpretación, analíticos primeros y analíticos segundos. Biblioteca Clásica Griega No. 115. Introducciones, Traducciones y Notas por: Miguel Candel Sanmartín. Madrid: Gredos.

. (1992). The essential Peirce: selected philosophical writings. Vol I-II. Edited by Nathan Houser and Christian Kloesel. Bloomington: Indiana University Press. 
. (s.f.). Writings of Charles S. Peirce: a chronological edition. Vol 1-8. Indiana University Press.

. (2012). Obra Filosófica Reunida. Vol. I-II. Traducido por Darin McNabb. Fondo de Cultura Económica.

Aristóteles. (1994). Acerca del Alma. Biblioteca Clásica Griega No. 14. Introducción, Traducción y Notas por: Tomás Calvo Martínez. Madrid: Gredos.

Beare, I. (1906). Greek Theories of Elementary Cognition: From Alcmeon to Aristotle. Oxford: Clarendon Press.

Bernstein, J. (1964). Peirce's Theory of Perception. In Studies in the Philosophy of Charles Sanders Peirce. Second Series. Edited by Edward Moore and Richard Robin, 165-189. Amherst: The University of Massachustts Press.

Brentano, F. (1977). The Psychology of Aristotle. Edited and translated by Rolf George. Berkeley: University of California Press.

Buchler, J. (1966). Charles Peirce's Empiricism. New York: Octagon Books.

Cashdollar, S. (1973). Aristotle's Account of Incidental Perception. Phronesis, 18(2), 156-175.

Flórez, J. (2013). El sinequismo, el realismo y el empirismo de Charles S. Peirce, aplicados a sus teorías de la percepción y del conocimiento. En Discusiones Filosóficas. Editorial Universidad de Caldas, 14(23), 233-252.

Gregoric, P. (2007). Aristotle on the Common Sense. Department of Philosophy, Faculty of Humanities and Social Sciences, University of Zagreb. Published to Oxford Scholarship online: september.

Owens, J. (1982). Aristotle on Common Sensibles and Incidental Perception. Phoenix, 36(3), 215-236.

Peirce, C. (1958). Collected Papers. Peirce. Vols. I-VI, eds. Charles Hartshorne and Paul Weiss, Arthur W. Burks (same publisher, 1958). Cambridge, MA: Harvard University Press, 1931-1935, vols. VII-VIII. 